\title{
LIMAX (LIMAX) SETICUS N. SP. FROM HIGH MOUNTAINS IN NEPAL (GASTROPODA: PULMONATA: LIMACIDAE)
}

\author{
ANDRZEJ WIKTOR ${ }^{1}$, ULRICH BÖSSNECK ${ }^{2}$ \\ ${ }^{1}$ Museum of Natural History, Wrocław University, 50-335 Wrocław, Poland \\ (e-mail: awiktor@biol.uni.wroc.pl) \\ ${ }^{2}$ Schillerstr. 17, 99198 Erfurt-Vieselbach, Germany \\ ABSTRACT: Limax seticus $\mathrm{n}$. sp. from Nepal belongs to a genus whose distribution range was believed to be lim- \\ ited to the Western Palaearctic, the ranges of other genera of the family Limacidae being also situated far from \\ the type locality. This alpine site (the highest situated locality known for slugs) on the foreland of a glacier and \\ the natural character of the habitat exclude the possibility of introduction. In its external appearance, struc- \\ ture of genitalia and of alimentary canal, L. seticus resembles the European $L$. cinereoniger, but it is five times \\ smaller and differs in some other characters.
}

KEY WORDS: slugs, Limax, new species, Nepal, distribution, altitudinal range

\section{INTRODUCTION}

The discovery of a representative of the genus Limax in Nepal is utterly amazing. All species of this genus occur in the Western Palaearctic, mainly in the Mediterranean and Central Europe. The easternmost locality of the genus is situated in the region of Kazan', where a single species was recorded. The whole family Limacidae has its representatives in the Western Palaearctic. In the east it reaches Kirgiz and Kashmir, but this concerns genera other than Limax
(HESSE 1926, LIKHAREV \& WIKTOR 1980, WIKTOR et al. 1999), and no limacid occurs south of the Himalayas.

Nowadays two large centres of diversification of these slugs can be distinguished. One is the Mediterranean in the broad sense, along with the Black Sea region and the Caucasus mountains, and the other is situated in Central Asia. The character of the habitat where the new slug was found precludes the possibility of introduction from any other part of the world.

\section{Limax (Limax) seticus $\mathbf{n}$. sp.}

Holotypus: Dudh Lekh near Sankha Lagna, Nepal, Chachour, distr. Bajura, prov. Seti Dudh (29 $56^{\circ} 09^{\prime \prime}$, $\left.81^{\circ} 40^{\prime} 32^{\prime \prime} \mathrm{E}\right)$, moraine of a glacier at the base of rocks, 4,700-4,800 m a.s.l., leg. U. BÖSSNECK \& A. WEIGEL, 1 July 2001, Mus. Nat. History, Wrocław University, Wrocław, Poland, No. MP 968.

Paratypi: collected with the holotype -3 adult specimens, including one with its penis everted, and 10 not completely mature: 1 adult and 3 juveniles in the Mus. Nat. Hist. Wrocław, Poland, No. MP 968; 1 adult and 4 juveniles in U. Bössneck coll.; 1 adult and 3 juveniles in the Nat. Hist. Mus. Erfurt, Germany No. NME 0421U.

Diagnosis: a medium-sized slug, live animals up to $38 \mathrm{~mm}$ long (when alcohol-preserved: $34 \mathrm{~mm}$ ). Back and sides deep black, keel black (!), sole with the lateral stripes blackish and the medial one nearly white. Around pneumostome a circular plate distinguishable (!). Keel reaching the posterior edge of mantle (!). Penis vermiform, ca 2.5 longer than the entire 
body. Genitalia are almost identical in shape with those of the European Limax cinereoniger Wolf, 1803. However, the new species is over five times smaller, the same pertaining to the genitalia, and its long keel, which is the same colour as the back, additionally distinctly differentiates this species from the European one.

Etymology: The name has been derived from the province of Seti, where the species was found.

\section{DESCRIPTION}

External appearance (Figs 1-2). The general habitus characteristic of the genus Limax s. str. Body narrow, the length of the largest specimen (holotypus) equalling $39 \mathrm{~mm}$, mantle length ca $12 \mathrm{~mm}$, body breadth slightly exceeding $5 \mathrm{~mm}$. Keel poorly arched, but reaching the posterior edge of mantle. Around pneumostome there is a circular plate distinguishable from the rest (like in the majority of Agriolimacidae). Skin sculpture delicate, the number of wrinkles between keel and pneumostome difficult to count about 20. Head, mantle, the rest of back, including keel and sides, uniformly deep black. Sole with the lateral stripes blackish, the medial one whitish. Mucus colourless.

Genitalia (Fig. 3). The largest specimen (holotype) and the paratypes are in the male phase of reproductive development, i.e. they have their gonads large in comparison with other parts of genitalia. Hermaphroditic duct almost straight. Albumen gland still small. Spermoviduct bears no special characters, but already has its male section (prostate) clearly distinguishable from the female one. Free oviduct section in the shape of a straight tube. Penis ca 2.5 times longer than the whole body, vermiform, slightly distended at the posterior end. Vas deferens opens to penis apically, but somewhat laterally. Penial retractor muscle attached in the immediate vicinity of the vas deferens outlet. Penis lacking any appendages (accessory organs). Right ommatophore crossing penis. Spermatheca elongated, roughly oval in shape, set on a duct which approximates to the container in length. This duct joins penis close to atrium, which is long,

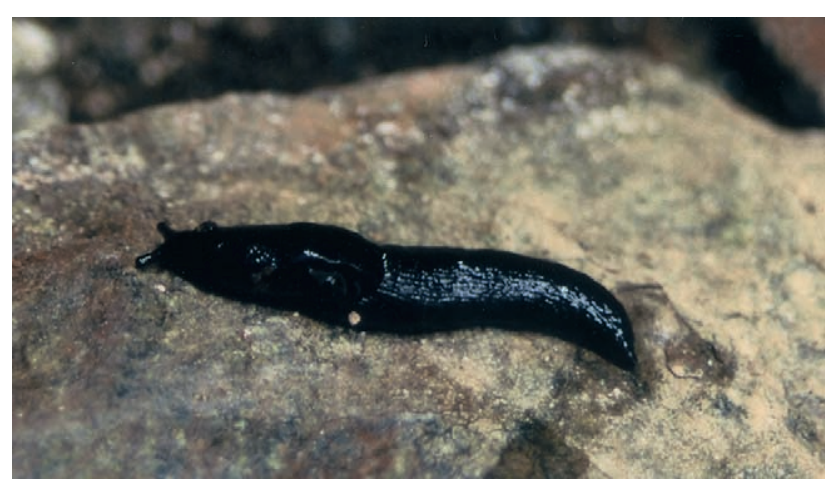

Fig. 1. Limax seticus n. sp. (photo U. BÖSSNECK) compared to this organ in other members of the genus Limax.

Alimentary canal (Fig. 4) shows all the characters typical of the genus Limax s. str., i.e. three loops, the last of which is the longest, and caecum lacking.

Habitat (Fig. 5). The slug was found on the moraine of a smallish glacier flowing from an unnamed mountain $6,000 \mathrm{~m}$ a.s.l. high, slightly above a postglacial lake. This zone has a very poor vegetation, growing in tufts. Humidity high or medium. The slugs hid under stones and at the base of rocks. They were not numerous - within 10 hours just a few specimens were collected. The new slug was accompanied by Pyramidula sp.

Observations of live slugs indicate that they were collected in their natural habitat, and were unlikely to have been introduced there. They were found at a very high altitude - ca 4,700 $\mathrm{m}$ a.s.1. The type locality (Fig. 6) is the highest situated locality of known slugs, only some Anadenidae being found above 4,500 m a.s.l. (WIKTOR 2001, WIKTOR \& AUFFENBERG 2002). The slug described occurs in a small population, finding shelter under stones in an alpine habitat (shown in the photo - Fig. 6).

\section{COMMENTS}

Identification of this slug in the field should not raise difficulties. It is the only known representative of Limacidae south of the Himalayas, and, what is more,

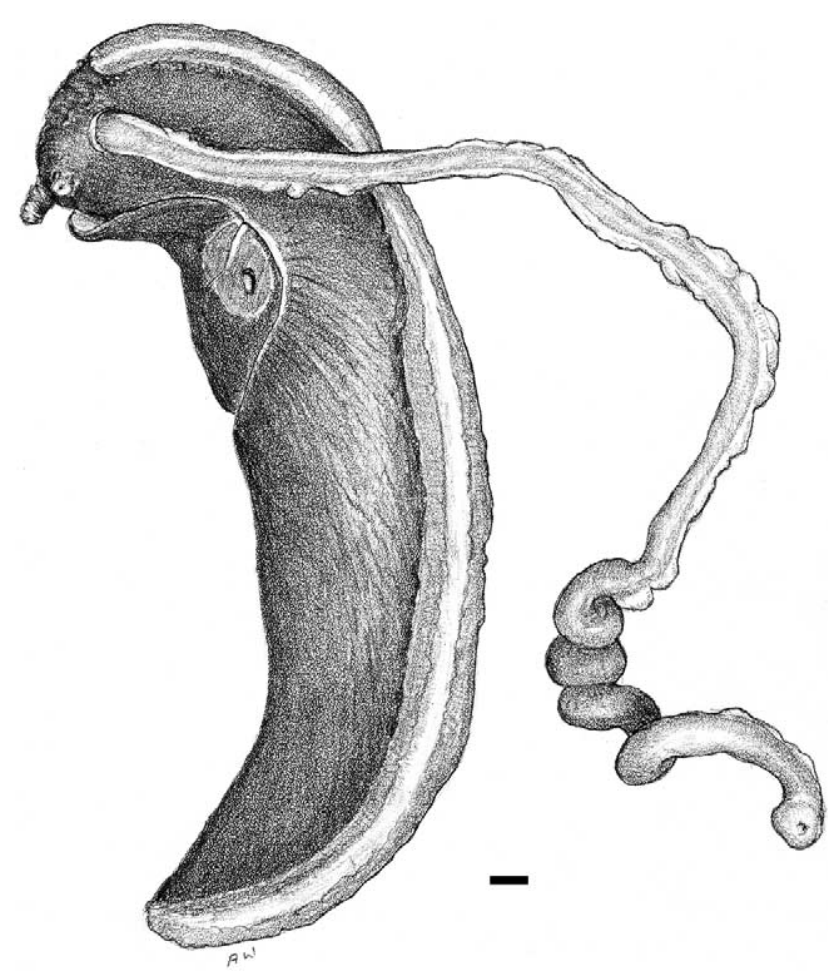

Fig. 2. A paratype of Limax seticus $\mathrm{n}$. sp. - the specimen with its penis everted. Scale bar $1 \mathrm{~mm}$ (fig. by A. WIKTOR) 
displaying all the characters typical of the family. Due to its relatively small size, body shape and black coloration it somewhat resembles the alpine (West-Palaearctic) forms of the genus Lehmannia Heynemann, 1862, particularly L. nyctelia (Bourguignat, 1861), a species which also has a long penis. Any possible doubts can be dispelled when the alimentary canals of the two species are compared - in all members of the

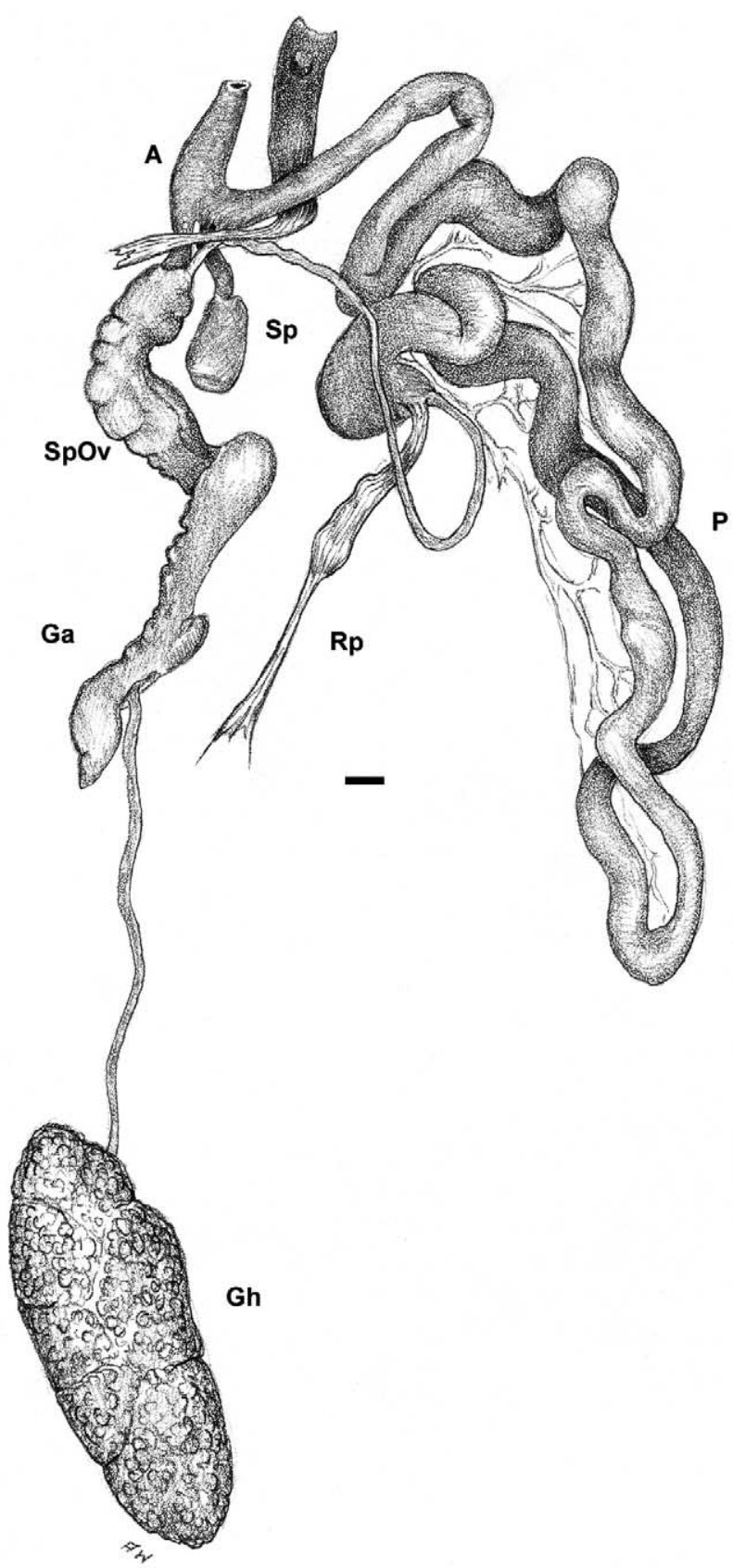

Fig. 3. Reproductive system of Limax seticus n. sp. - holotype. Scale bar $1 \mathrm{~mm}$ (fig. by A. WIKTOR). A - atrium; $\mathrm{Ga}$ - glandula albuminalis; Gh - glandula hermaphroditica; P - penis; Rp - musculus retractor penis; $\mathrm{Sp}$ - spermatheca; SpOv - spermoviductus genus Lehmannia the caecum is long and the last intestinal loop, connected with it, is very short. Also slugs inhabiting Central Asia are evidently different with respect to their anatomical structure.

We are unable to explain the origin of this slug, a representative of a Western-Palaearctic genus in such a remote region, where a completely different malacofauna occurs. Two possibilities should be considered: either the one concerned is an isolated locality of an endemic species, resulting from dispersal, or Limacidae have a considerably wider distribution range, inhabiting also vast areas of India and Nepal, and we only lack pertinent information. These regions are only fragmentarily explored with respect to the slug fauna, and only representatives of Anadenidae, which are large slugs, have so far been recorded from this area.

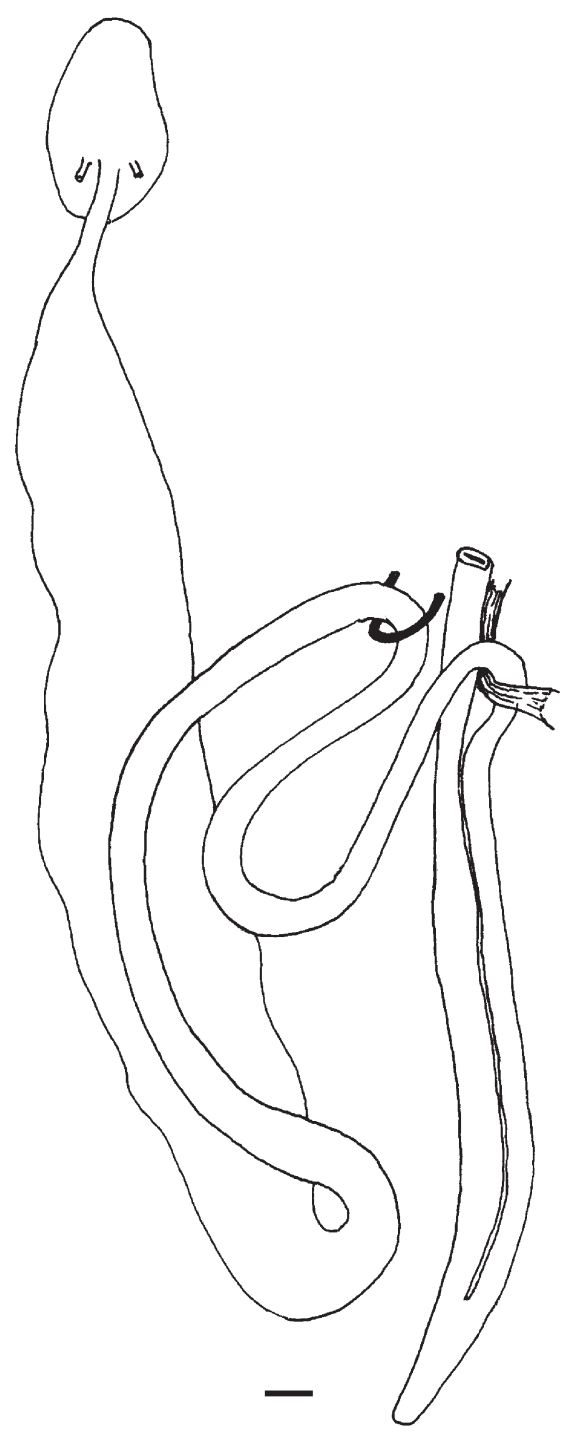

Fig. 4. Limax seticus n. sp. - alimentary canal of the holotype. Scale bar $1 \mathrm{~mm}$ (fig. by A. WIKTOR) 


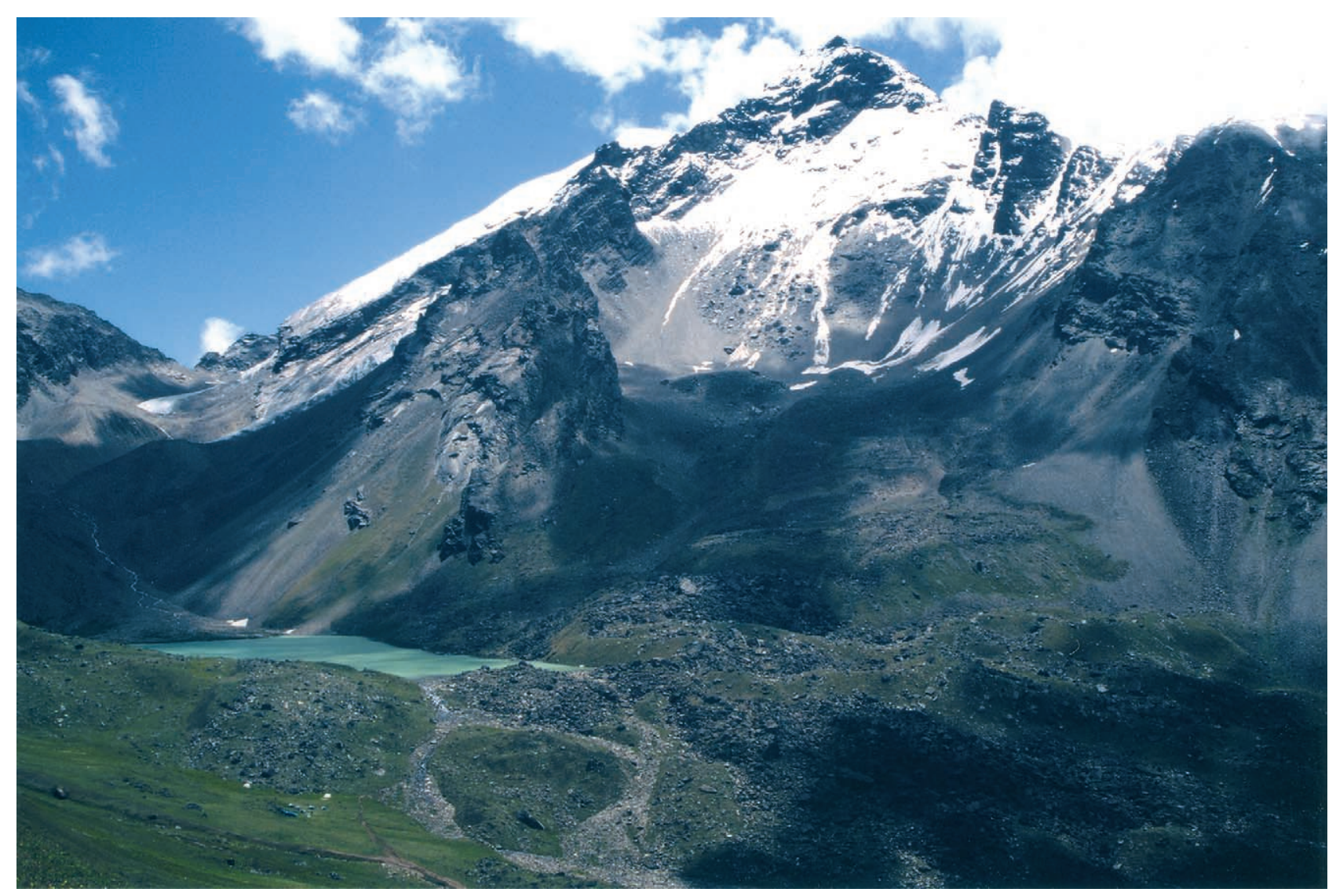

Fig. 5. The habitat where Limax seticus n. sp. was collected (photo U. BöSSNECK)

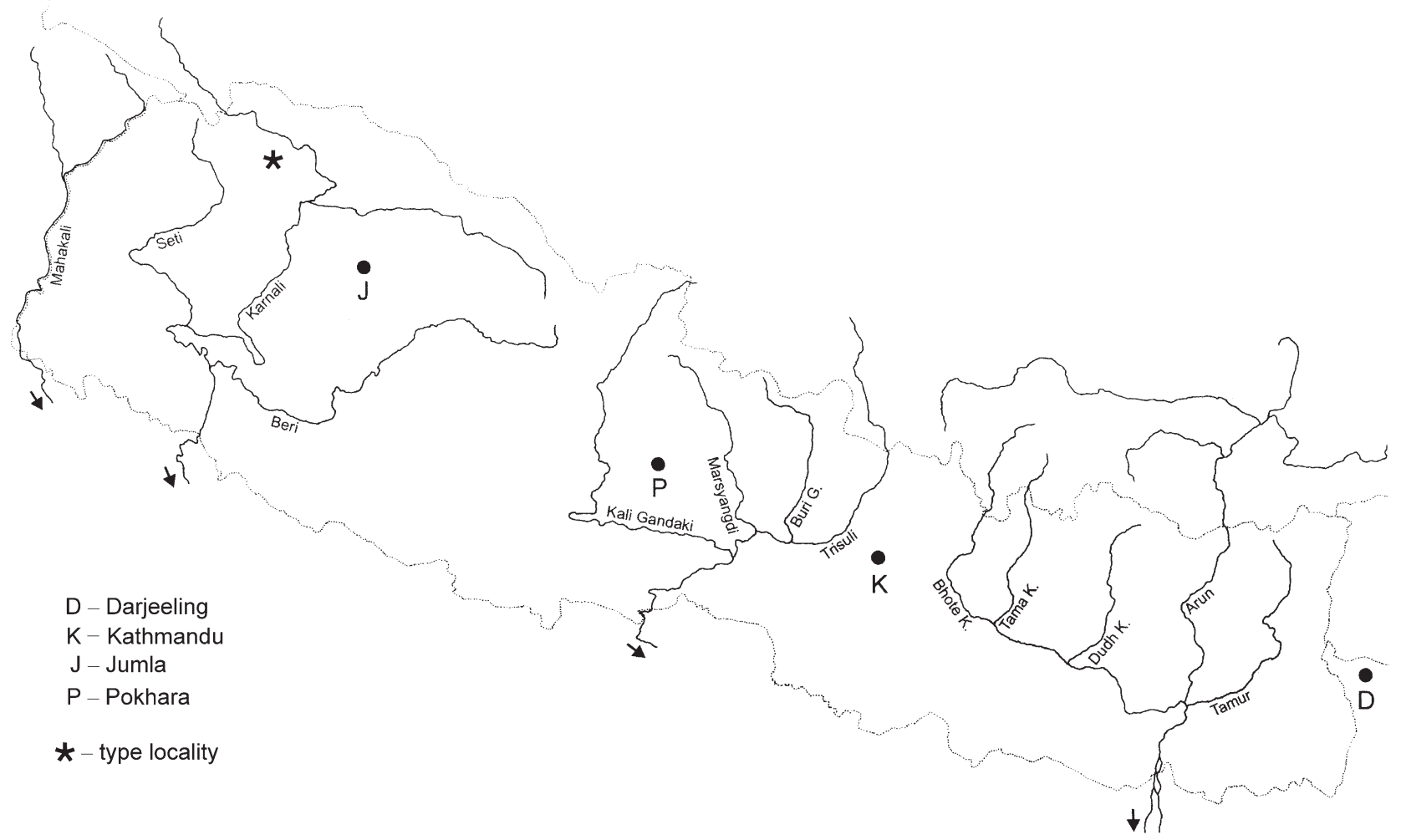

Fig. 6. Map of Nepal showing the type locality of Limax seticus n. sp. 


\section{REFERENCES}

HESSE P. 1926. Die Nacktschnecken der palaearktischen Region. Arch. Moll. 2: 1-152.

LIKHAREV I. M., WIKTOR A. 1980. Slizni fauny SSSR i sopredelnykh stran (Gastropoda terrestria nuda). Fauna SSSR. Mollyuski III(5): Nauka. Leningrad.

WikTor A. 2001. A review of Anadenidae (Gastropoda: Pulmonata), with description of a new species. Folia Malacol. 9: 3-26.
Wiktor A., AuffenberG K. 2002. Contribution to the knowledge of the terrestrial slugs of Pakistan. Folia Malacol. 10: 9-15.

WikTOR A., NAGgs F., Kumar P. 1999. Turcomilax (Taulimax) oli sp. n. from the Kuman Himalaya, India (Gastropoda: Pulmonata: Limacidae). Malak. Abh. 19: 225-231.

Received: August 20th, 2004

Accepted: September 29th, 2004 